\title{
Unusual theropod eggshells from the Early Cretaceous Blesa Formation of the Iberian Range, Spain
}

Miguel Moreno-Azanza, José I. Canudo, and José M. Gasca

Acta Palaeontologica Polonica 59 (4), 2014: 843-854 doi: http://dx.doi.org/10.4202/app.2012.0069

Trigonoolithus amoae oogen. et oosp. nov. is described on the basis of abundant eggshell fragments from the La Cantalera 1 site in the Early Cretaceous (early Barremian) Blesa Formation, Teruel Province, northern Spain. The surface ornamentation, the most diagnostic feature of the new oogenus, consists of closely spaced sub-triangular or rounded protuberances that have not previously been reported in any other ootaxon. The eggshells present three distinct layers, with a gradual transition between prismatic and mammillary layers, and a poorly developed external layer with progressive prismatic to external layer transition, a combination of characters that allows them to be assigned to Prismatoolithidae. Phylogenetic analyses based on oological characters place Trigonoolithus at the base of Prismatoolithidae.

Key words: Dinosauria, Theropoda, Prismatoolithidae, parataxonomy, dinosaur eggshells, Barremian, Cretaceous, Blesa Formation, Teruel Province, Spain.

Miguel Moreno-Azanza, [mmazanza@unizar.es], José I. Canudo [jicanudo@unizar.es ], and José M. Gasca [gascajm@unizar.es], Grupo Aragosaurus-IUCA. Área de Paleontología, Facultad de Ciencias, Universidad de Zaragoza. Pedro Cerbuna 12, 50009 Zaragoza, Spain.

This is an open-access article distributed under the terms of the Creative Commons Attribution License (for details please see creativecommons.org), which permits unrestricted use, distribution, and reproduction in any medium, provided the original author and source are credited. 
